\title{
A Comparison of Cochlear Nerve Size in Normal-Hearing
}

\section{Adults Using MRI}

Christopher Heining, Theofano Tikka, Steve Colley, Laura

Zilinskiene, Chris Coulson. University Hospitals

Birmingham, Mindelsohn Way, Edgbaston, Birmingham,

B15 2GW

\section{INTRODUCTION}

The prognostic relevance of cochlear nerve size on cochlear implantation is currently not well-established. Increasing evidence is emerging that cochlear nerve hypoplasia is a predictor of poor outcome post cochlear implantation, and that cochlear nerve size correlates with duration of hearing loss[1,2,3,4]. Measuring the size of the cochlear nerve before cochlear implantation may be helpful in preoperative counselling of the patients as well as in potentially determining the eligibility and timing for the operation [2].

The present study investigates the currently unproven hypothesis that there is no difference in cochlear nerve size between the two ears in normal-hearing adults.

\section{MATERIALS AND METHODS}

All patients with tinnitus requiring $\mathrm{MRI}$ to exclude a cerebellopontine angle lesion presenting to an Ear, Nose and Throat (ENT) outpatient clinic between January 2012 and August 2013 were retrospectively assessed to select study subjects with normal hearing and no nerve pathology. Patient demographics, pure tone audiometry (PTA) averages at frequencies of $500 \mathrm{~Hz}, 1 \mathrm{kHz}, 2 \mathrm{kHz}$, and $4 \mathrm{kHz}$, side of the tinnitus, and any predisposing factors for cochlear or facial nerve disorders were recorded.

Exclusion criteria were abnormal hearing, described as average PTA scores equal to or greater than 30 at the four measured frequencies, history of facial nerve palsy, previous ear surgery, and demyelinating disease (Table 1).

\begin{tabular}{|l|l|}
\hline Exclusion criterion & $\begin{array}{l}\text { Number } \\
\text { patients }\end{array}$ \\
\hline Abnormal hearing on PTA & 48 \\
\hline Facial nerve palsy / previous inner ear surgery & 2 \\
\hline Demyelinating disease & 1 \\
\hline No MRI scan & 2 \\
\hline
\end{tabular}

Table 1. Exclusion criteria in a cohort of patients with normal hearing and unilateral tinnitus

\begin{tabular}{|c|c|c|c|}
\hline & $\begin{array}{l}\text { Right cochlear } \\
\text { nerve }\end{array}$ & $\begin{array}{l}\text { Left cochlear } \\
\text { nerve }\end{array}$ & $p$ \\
\hline Mean \pm SD, $\mathrm{mm}^{2}$ & $1.16 \pm 0.34$ & $1.16 \pm 0.30$ & 0.827 \\
\hline \multirow[t]{2}{*}{ Range, $\mathrm{mm}^{2}$} & $0.75-2.30$ & $0.71-1.90$ & \\
\hline & $\begin{array}{l}\text { Right facial } \\
\text { nerve }\end{array}$ & Left facial nerve & $p$ \\
\hline Mean $\pm S D, m^{2}$ & $0.84 \pm 0.23$ & $0.86 \pm 0.25$ & 0.723 \\
\hline Range, $\mathrm{mm}^{2}$ & $0.58-1.68$ & $0.51-1.62$ & \\
\hline
\end{tabular}

Table 2. Cochlear and facial nerve size in normal-hearing adults with tinnitus

1. Kutz JW Jr et al.Cochlear implantation in children with cochlear nerve absence or deficiency. Otol Neurotol 2011; 32: 956-61 2. Kim BG et al. Correlation of cochlear nerve size and auditory performance after cochlear implantation in postlingually deaf patients. JAMA Otolaryngol Head Neck Surg 2013; 139: 604-9.

3. Russo EE et al. Cochlear nerve size evaluation in children with sensorineural hearing loss by high-resolution magnetic resonance . 4. Herman B, Angeli S. Differences in cochlear nerve cross-sectional area between normal hearing and postlingually deafened patients
MRI. Otolaryngol Head Neck Surg 2011; 144: 64-6.

imaging in elderly patients with sensorineural hearing loss. Radii Me , et al. Evaluation of coc

6. Nakamichi R, Yamazaki M, Ikeda M, Isoda H, Kawai H, Sone M, et al. Establishing normal diameter range of the cochlear and facia nerves with 3D-CISS at 3T. Magn Reson Med Sci 2013; 12: 241-7.

7. Kang WS, Hyun SM, Lim HK, Shim BS, Cho JH, Lee KS. Normative diameters and effects of aging on the normal-hearing Korean ears using 3.0-tesla magnetic resonance imaging. Laryngoscope $2012 ; 1$

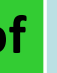

No significant differences in nerve size were found between genders, between scans on different strength MRI scanners, age or side of tinnitus.

\section{DISCUSSION}

The current study demonstrates that sizes of the cochlear and facial nerves are symmetrical in normal-hearing adults. There was very good inter-rater agreement between the measurements of the two observers, and the mean nerve sizes in this study were comparable to normal diameters previously published [6,7]. Previous research has demonstrated that hearing loss may cause anatomical and histological changes in the auditory pathway $[8,9]$. Clearly, these results hinge on whether the nerves are symmetrical in "normal" ears, which we have now proven.

One of the limitations of our study was poor quality of the MRI images, requiring exclusion of $>50 \%$ of study individuals. The main reasons the nerve sizes could not be measured adequately were movement artefact, nerve clustering in the internal auditory meatus (IAM) or adherence to the walls of the IAMs.

\section{CONCLUSION}

This study establishes that cochlear and facial nerve sizes are symmetrical in normal-hearing adults and are not affected by age or gender. The adequacy of the MRI imaging to allow nerve size measurement remains quite poor currently, but as quality of scans and the software used to interpret them improves, so should our ability to assess nerve size. Nerve size assessment should remain an active area of research in otological disease particularly in the context of potential cochlear implants. 